\title{
Article \\ Analysis and Design of Inertia for Grid-Tied Electric Vehicle Chargers Operating as Virtual Synchronous Machines
}

\author{
Chenming Liu (i) and Jingyang Fang *(i) \\ School of Control Science and Engineering, Shandong University, Jinan 250100, China; \\ liuchenming@mail.sdu.edu.cn \\ * Correspondence: jingyangfang@sdu.edu.cn
}

Citation: Liu, C.; Fang, J. Analysis and Design of Inertia for Grid-Tied Electric Vehicle Chargers Operating as Virtual Synchronous Machines. Appl. Sci. 2022, 12, 2194. https://doi.org/10.3390/app12042194 Academic Editor: Adel Razek

Received: 25 January 2022 Accepted: 17 February 2022 Published: 19 February 2022

Publisher's Note: MDPI stays neutral with regard to jurisdictional claims in published maps and institutional affiliations.

Copyright: (C) 2022 by the authors. Licensee MDPI, Basel, Switzerland. This article is an open access article distributed under the terms and conditions of the Creative Commons Attribution (CC BY) license (https:// creativecommons.org/licenses/by/ $4.0 /)$.

\begin{abstract}
Renewable energy resources (RES), e.g., solar photovoltaic (PV), wind energy, and electric vehicles (EVs) are extensively integrated into modern power electronics-based power systems due to their sustainable and environmentally friendly features. This has gradually reshaped the frequency regulation structure of power systems. Specifically, the duty of frequency regulation, previously supported by synchronous generators, will be taken over by grid-tied power converters (such as EV chargers), which can be controlled as virtual synchronous machines (VSMs) to mimic the inertial response of synchronous generators. However, being different from synchronous generators, VSMs enable fast frequency regulation. As a consequence, it is identified in this paper that the elimination of frequency oscillations is possible. Therefore, instead of simply increasing inertia for oscillations suppression, the desirable inertia coefficient can be different for various cases. In order to illustrate this point, relationships between several important performance indices, such as the rate-of-changeof-frequency, frequency nadir, overshoot, settling time, and inertia coefficient, are analyzed in detail. Furthermore, a straightforward method for designing the optimal inertia coefficient for VSMs is put forward. Finally, experiment results obtained from a 1-kW three-phase VSM prototype are demonstrated to validate the effectiveness of the theoretical analysis and proposed design method.
\end{abstract}

Keywords: electric vehicle (EV); frequency regulation; renewable energy resources (RES); power system inertia; virtual synchronous machine (VSM)

\section{Introduction}

Throughout human history, energy has always been indispensable for various fields from industry to domestic life. Ever since the widespread use of electricity over one hundred years ago, it has remained a desirable form of energy due to its advantages, including convenient utilization and efficient conversion. Traditionally, primary energy sources, such as coal, oil, natural gas, and nuclear fuel, are used in such a way that their internal chemical energy is converted into electrical energy through first heating the steam/gas turbines and then driving synchronous generators in centralized power plants. Although being effective in electricity generation, this approach will inevitably cause environmental issues. In addition, such primary energy sources are very limited in nature and only capable of supporting for less than one hundred or several hundreds of years. In order to address the ever-challenging energy crisis and environmental issues, renewable energy resources (RES), e.g., wind energy and solar photovoltaic (PV), are deployed extensively in modern power systems. Being different from fossil fuels, these RES are normally coupled to the power grid through power electronic converters instead of turbines and synchronous generators [1]. Moreover, electric vehicles (EVs) are replacing conventional vehicles due to eco-friendly features and performance improvements [2,3]. As a consequence, power electronics are ubiquitous in modern power systems [4].

One prominent feature of power systems is the real-time power balance between their generation and utilization. Once the imbalance of active power occurs, the system 
frequency will vary until the system reaches another steady state of power balance. For traditional power systems, synchronous generators absorb or release their rotational kinetic energy during frequency dynamics to help slow down the frequency change. In order to quantify this effect, the concept of inertia is proposed, and it is defined as the ratio of kinetic energy to the rated power of synchronous generators [5]. In modern power electronics-based power systems, synchronous generators are gradually replaced by gridtied dc-ac power converters (inverters). However, since these converters normally operate to extract the maximum power from RES without absorbing/providing any kinetic energy, the system inertia contributed by synchronous generators continues to reduce [6]. This leads to larger frequency deviations and changing rates during frequency events, which may further cause undesirable loading, shedding, or even blackouts [7].

One effective approach to increase the system inertia during frequency events is the adoption of energy storage systems for inertia emulation [8]. In [7], an additional energy storage system consisting of supercapacitors was employed to provide frequency support in electrical islands with large shares of RES. After a generation outage, i.e., a frequency event, the energy storage system promptly injected power into the grid, leading to reduced system frequency deviations and changing rates. Similarly, a supercapacitor-based energy storage system was incorporated in a wind generation system to produce virtual inertia for compensating frequency disturbances as well as intermittency caused by wind fluctuations in [9]. Despite those additional energy storage systems allowing a fast reaction to power imbalance, this approach brings other concerns, e.g., increased system complexity and maintenance costs.

Another interesting attempt is to utilize existing energy storage units in EVs for frequency regulation. With a desirable controller, grid-tied converters in EVs can contribute grid services, known as vehicle-to-grid (V2G) services. When operating as synchronous generators, grid-tied converters are known as virtual synchronous generators (VSG) [10], virtual synchronous machines (VSM) [11], or synchronverters [12]. Notably, when imitating synchronous generators, grid-tied converters can be controlled to achieve different levels or extents of emulation. In [11-13], converters were regulated based on the comprehensive mathematical model covering all the dynamics of synchronous generators to achieve power regulation and load sharing. However, the presented model suffers from its inherent complexity. In addition, models regarding frequency regulators, i.e., the speed governor and turbine, are excluded from the analysis. References [14-18] claimed that inverters were not necessarily controlled exactly as synchronous generators. As long as the essential electrical-mechanical behavior of synchronous generators, which is described by the wellknown swing-equation [5], was incorporated in VSMs, it would exhibit a similar inertial response as synchronous generators under frequency events. In order to supplement this model, behaviors of frequency regulators, such as speed governor, were added to VSMs in $[16,19,20]$. This completed the frequency regulation structure. Moreover, it was identified in [21-25] that the frequency stability of power electronics-based power systems could be improved since VSMs are capable of responding much faster to frequency events than conventional synchronous generators. In order words, VSMs enable fast frequency regulation and power balance. However, this may cause remarkable differences in the influence of inertia on frequency regulation from traditional power systems, which was not discussed in previous research. Moreover, it is possible to dynamically change the inertia coefficient of VSMs even during frequency events, although this is achieved at the expense of increased control complexity [26-29]. Therefore, it is quite necessary to have a guideline for the design of inertia coefficients.

This paper aims to analyze the influence of inertia provided by grid-tied converters in EVs on frequency regulation performances, where synchronous generators are replaced by fast-response VSMs. Furthermore, a design method for the optimal inertia coefficient will be presented. The system schematics and structure of frequency regulation will be provided in Section 2. In Section 3, the relationships between several important performance indices, such as the rate-of-change-of-frequency (ROCOF), frequency nadir (peak), overshoot, 
settling time, and inertia coefficient, will be derived. Based on these indices, the design of optimal inertia coefficients will be discussed in Section 4. Experiment results will be demonstrated in Section 5 to validate the correctness of the theoretical analysis and feasibility of the inertia design. Finally, Section 6 concludes the main contribution of this paper.

\section{System Schematics and Frequency Regulation Structure}

\subsection{System Schematics}

The increasing requirements for reducing carbon footprint and energy conservation have challenged traditional power systems. As an enabling technology to address these concerns, power electronics are ubiquitous in modern power systems. In particular, the function of frequency regulation previously provided by synchronous generators will be gradually taken over by grid-tied power converters, which are controlled as virtual synchronous machines (VSMs) to mimic the frequency regulation characteristics of synchronous generators [11-13]. Figure 1 illustrate the schematic diagram of a typical grid-tied EV charger operating as a VSM. As observed, the VSM serves as an interface between renewable generators and electric loads.

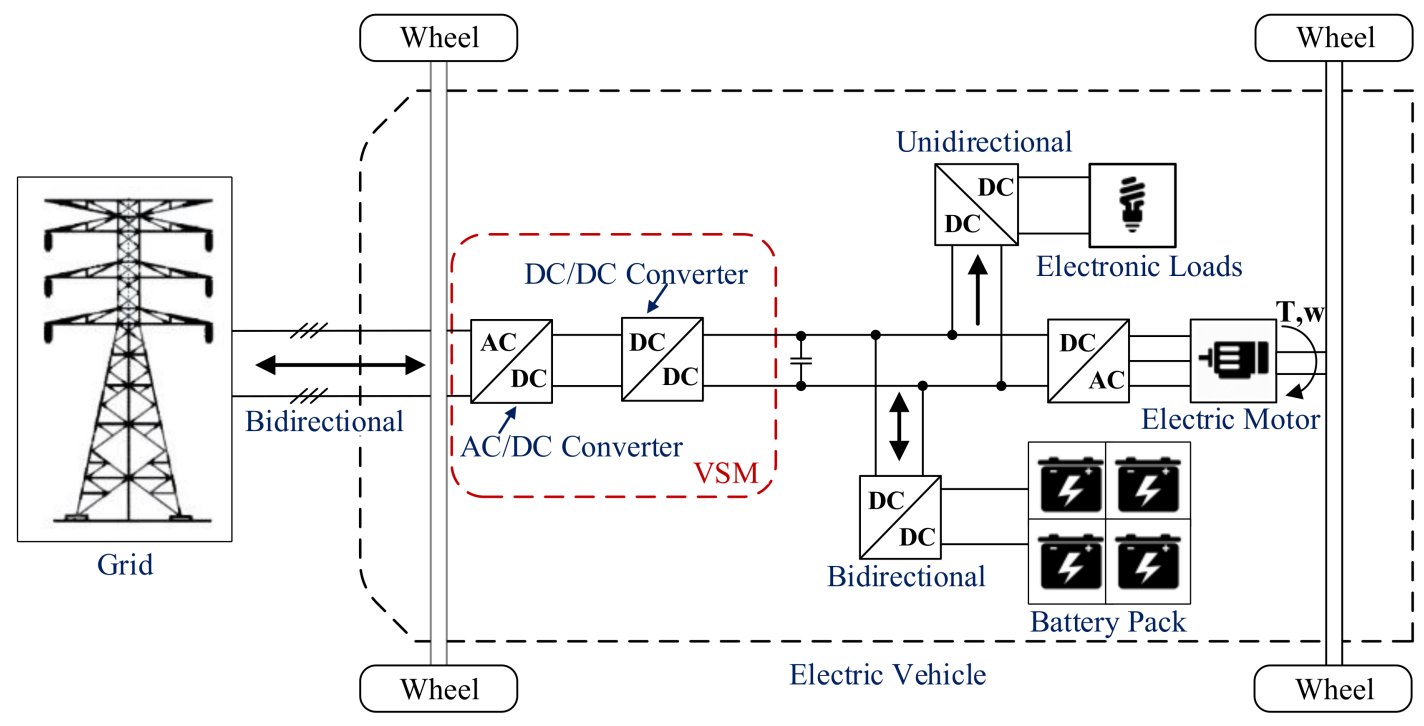

Figure 1. Schematic diagram of a grid-tied EV charger operating as a VSM.

\subsection{Structure of Frequency Regulation}

Figure 2 demonstrate the structure of frequency regulation based on the conventional frequency regulation model, where the behaviors of the speed governor, reheat turbine, synchronous generator, and electric load are included [5]. In Figure 2, $R$ designates the droop coefficient, whose physical meaning is to properly allocate the output power of synchronous generator $P_{m}$ according to the change of system frequency $\omega_{r}$ so as to accurately share the load among various synchronous generators. $T_{G}$ refers to the time constant of the speed governor, and it is introduced by the time delay of the actuator. $F_{H P}, T_{R H}$, and $T_{C H}$ are the coefficients of the reheat turbine. Among these coefficients, $T_{R H}$ representing the time constant of the reheat turbine normally plays a decisive role. With a typical value of $7 \mathrm{~s}, T_{R H}$ is far greater than the other coefficients [5]. $H$ denotes the combined inertia coefficient of synchronous generator and turbine, which is defined as the ratio of rotational kinetic energy to the rated power (normally ranges from 2-10 s [5]). Its significance was emphasized many times by the previous references [21-29]. Generally, it is believed that the increased penetration of renewable energy resources leads to reduced system inertia, which will significantly deteriorate the frequency and angle stability of power electronicsbased power systems. In order to address this issue, various approaches were proposed to increase the inertia coefficient $H[7,9]$. $D$ stands for the damping factor of loads, which 
indicates that the power consumption of frequency-dependent loads will change when the system frequency deviates from its nominal value.

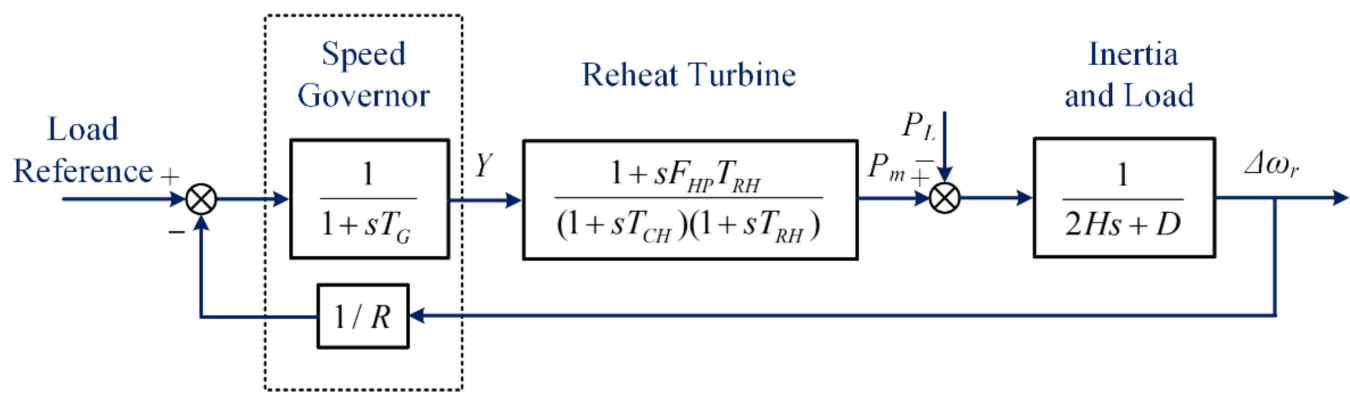

Figure 2. Structure of frequency regulation based on the conventional frequency regulation model.

The structure of frequency regulation based on VSMs is shown in Figure 3. Being different from Figure 2, the model of the turbine is excluded from this control structure so that the dynamics of frequency regulation can be improved while the other control blocks remain unchanged.

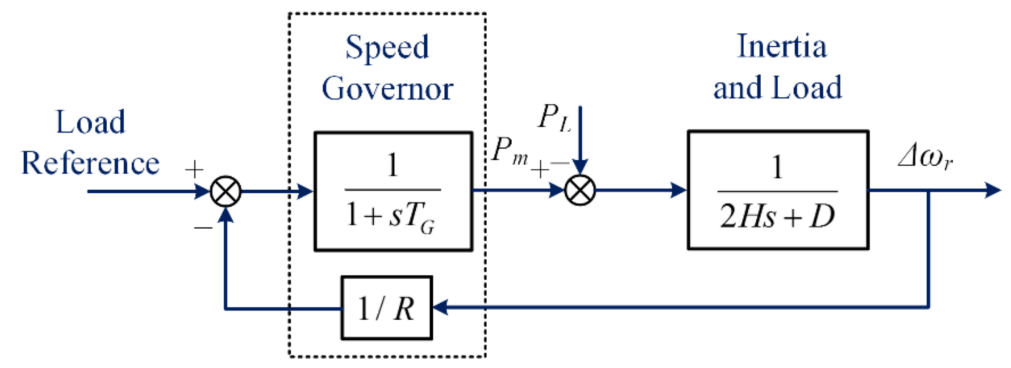

Figure 3. Structure of frequency regulation based on VSMs.

In Figure 3 , the transfer function from the variation of load power $\Delta P_{L}$ to the frequency variation $\Delta \omega_{r}$ can be derived as:

$$
G_{P_{L} \rightarrow \omega_{r}}(s)=\frac{\Delta \omega_{r}}{\Delta P_{L}}=\frac{-R\left(1+s T_{G}\right)}{(2 H s+D)\left(1+s T_{G}\right) R+1}=G_{0} \cdot \frac{s+z_{1}}{s^{2}+2 \zeta \omega_{n} s+\omega_{n}^{2}}
$$

where $z_{1}$ denotes the zero of $G_{P L \rightarrow \omega r}(s), \omega_{n}$ represents the undamped natural frequency, and $\zeta$ stands for the damping ratio. These parameters can be further represented as

$$
G_{0}=-\frac{1}{2 H}, z_{1}=\frac{1}{T_{G}}, \omega_{n}=\sqrt{\frac{D R+1}{2 H R T_{G}}}, \zeta=\frac{\left(2 H+D T_{G}\right)}{4 H T_{G}} \sqrt{\frac{2 H R T_{G}}{D R+1}}
$$

\section{Influence of Inertia on Frequency Regulation}

\subsection{Damping Factor Analysis}

According to the classic control theory, the damping factor $\zeta$ has a great influence on the second-order system described by (1). In order to illustrate this effect, the pole-zero map and step response of $G_{P L \rightarrow \omega r}(s)$ are, respectively, demonstrated in Figure 4a,b. In Figure $4 \mathrm{a}$, only zero $z_{1}$ is denoted as a circle while the poles $p_{1}$ and $p_{2}$ are represented by crosses. As seen, for the case of $\zeta<1, p_{1}$ and $p_{2}$ are conjugate complex poles. One special case is $\zeta=1$, where $p_{1}=p_{2}$ is satisfied. Under the condition that $\zeta>1, p_{1}$ and $p_{2}$ become real poles. It is noted from Figure $4 \mathrm{~b}$ that as $\zeta$ increases from less than one to be greater than one, oscillations of system frequency gradually disappear. 


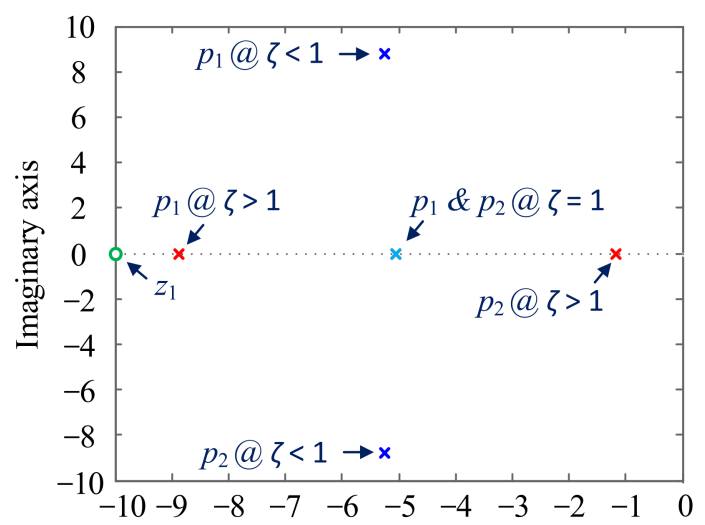

(a) Pole-zero map

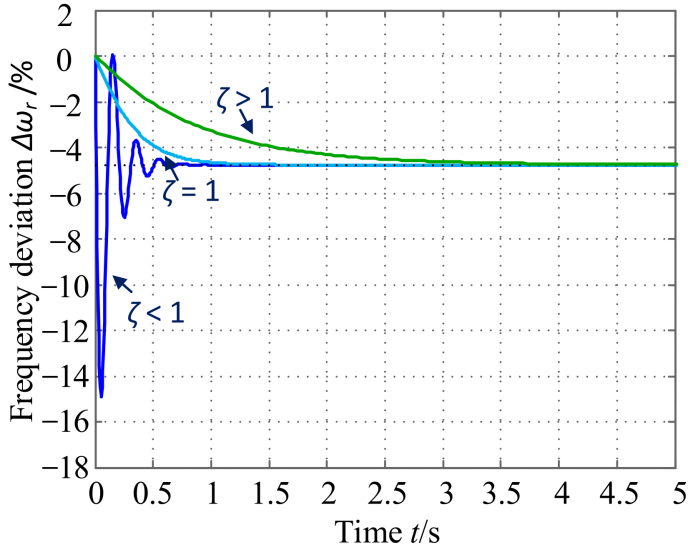

(b) Step response

Figure 4. Influence of damping factor $\zeta$ on $G_{P L \rightarrow \omega r}(s)$.

The relationships of $\zeta$ with $H$ and $T_{G}$ are presented in Figure 5. One observation from Figure 5 a is that $\zeta \geq 1$ may only occur when $T_{G}$ is small enough. For a relatively large $T_{G}$, e.g., $7 \mathrm{~s}, \zeta$ will never exceed one even when $H$ is as large as $50 \mathrm{~s}$. It should be mentioned that the conventional frequency regulation model shown in Figure 2 can be replaced by the simplified model shown in Figure 3 as long as the effect of the turbine is considered. This effect can be emulated by $T_{G}$, e.g., $T_{G}=T_{R}=7 \mathrm{~s}$. Under this approximation, the damping factor $\zeta$ will always be smaller than one [see Figure 5a]. Consequently, frequency oscillations will exist and can only be attenuated with the increase of $H$ (increase of $\zeta$ ). This was the basic motivation for previous researchers to increase the system inertia coefficient in power systems.

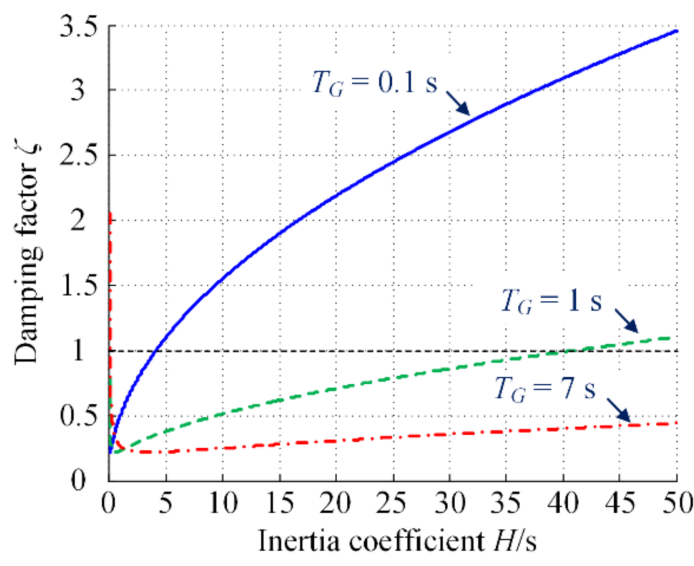

(a) Top view

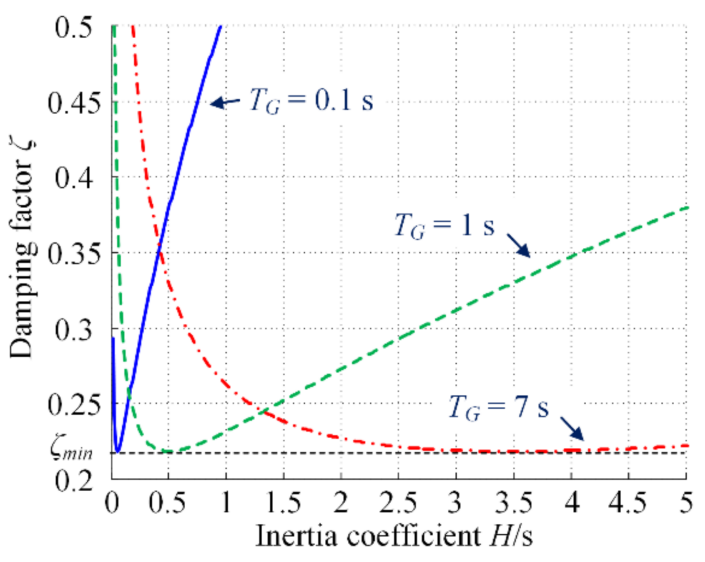

(b) Zoom-in view

Figure 5. Variation of $\zeta$ versus $H$ and $T_{G}$.

Additionally, it is clear from Figure $5 b$ that there exists one particular $H$ for $\zeta$ to be minimal. Its expression can be derived by first differentiating the fourth equation of (2) with respect to $H$ and then letting it be zero:

$$
\frac{d \zeta}{d H}=\sqrt{\frac{2 R T_{G}}{D R+1}} \cdot\left(\frac{1}{4 T_{G} \sqrt{H}}-\frac{D}{8 H \sqrt{H}}\right)=0 \Rightarrow H=\frac{D T_{G}}{2}
$$

It should be highlighted that the design of $H \leq D T_{G} / 2$ is avoided in practice. Although this design may introduce the same or even larger values of $\zeta$ as compared with the 
design of $H>D T_{G} / 2$, it does not necessarily translate into fewer oscillations and smaller overshoots, and this statement will be proven in Appendix A. Henceforth, $H>D T_{G} / 2$ is always satisfied unless otherwise stated. Substituting (3) into the fourth equation of (2), the expression of minimal $\zeta$ can be obtained as

$$
\zeta \sqrt{\frac{D R}{D R+1}}_{\text {min }}
$$

where $\zeta_{\min }$ represents the minimal value of $\zeta$, which is independent of $H$ and $T_{G}$.

The frequency responses of systems with $T_{G}=7 \mathrm{~s}$ and $T_{G}=0.1 \mathrm{~s}$ under a step-up load change are, respectively, demonstrated in Figure $6 a, b$. As indicated by Figure 6a, frequency oscillations are observable and can be attenuated with a larger inertia coefficient $H$ because the damping factor $\zeta$ increases as $H$ increases, which is consistent with the conclusion drawn from Figure 5. In contrast, it can be noted from Figures $5 \mathrm{a}$ and $6 \mathrm{~b}$ that the damping factor $\zeta$ becomes larger than one for the case of $T_{G}=0.1 \mathrm{~s}$ when $H=5$ or $10 \mathrm{~s}$. In this case, no oscillation is observable. The only effect of increasing $H$ is to prolong the dynamics of frequency regulation. Therefore, it is possible to employ a small $H$ under this condition.

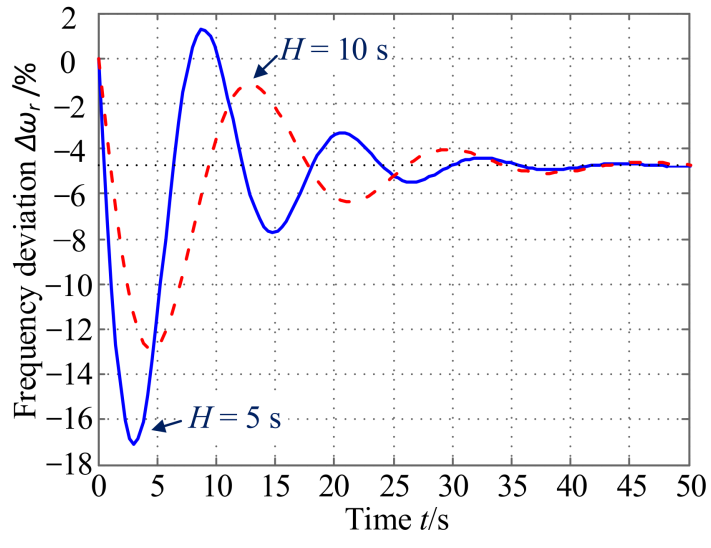

(a) $T_{G}=7 \mathrm{~s}$

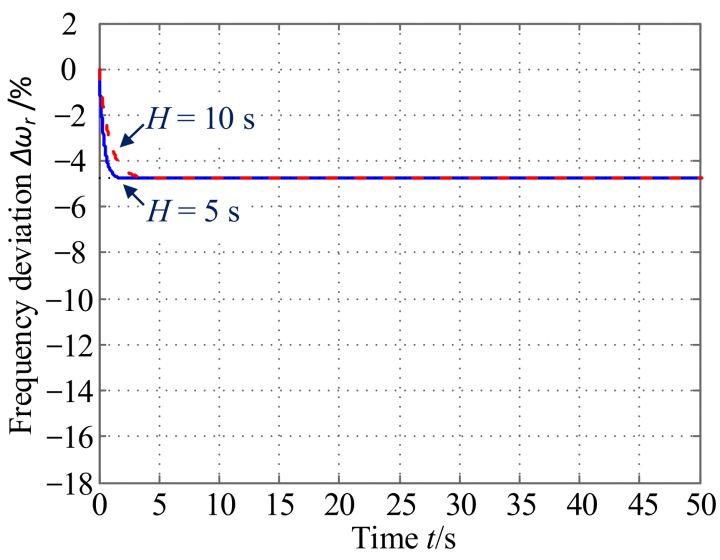

(b) $T_{G}=0.1 \mathrm{~s}$

Figure 6. System frequency responses under a step-up load change.

\subsection{Inertia Coefficient Analysis}

In order to fully understand the influence of inertia coefficient $H$ on the performances of frequency regulation, the expressions of several important performance indices such as the steady-state frequency, rate-of-change-of-frequency (ROCOF), frequency nadir (peak), frequency overshoot, and settling time will be derived in this subsection based on (1). Since these expressions take different forms for different values of $\zeta$, three cases with different ranges of $\zeta$, i.e., $\zeta<1, \zeta=1$, and $\zeta>1$, will separately be discussed.

\subsection{1. $\zeta<1$ Case}

Considering the case of $\zeta<1$, when a step-up load change occurs, the system frequency response can be expressed in the s domain as follows:

$$
f_{r}(s)=\frac{G_{P_{L} \rightarrow \omega}(s)}{s}=G_{0}\left\{\frac{1}{\omega_{d}} \cdot \frac{\omega_{d}}{\left(s+\zeta \omega_{n}\right)^{2}+\omega_{d}^{2}}+\frac{z_{1}}{\omega_{n}^{2}} \cdot\left[\frac{1}{s}-\frac{s+\zeta \omega_{n}}{\left(s+\zeta \omega_{n}\right)^{2}+\omega_{d}^{2}}-\frac{\zeta \omega_{n}}{\omega_{d}} \cdot \frac{\omega_{d}}{\left(s+\zeta \omega_{n}\right)^{2}+\omega_{d}^{2}}\right]\right\}
$$

where

$$
\omega_{d}=\omega_{n} \sqrt{1-\zeta^{2}}
$$


The time-domain expression of frequency response $f_{r}(t)$ can be obtained by taking the inverse Laplace transform of (5):

$$
f_{r}(t)=L^{-1}\left[f_{r}(s)\right]=G_{0}\left\{\frac{z_{1}}{\omega_{n}^{2}}-e^{-\zeta \omega_{n} t} \cdot A \cdot \sin \left(\omega_{d} t+\beta\right)\right\}
$$

where

$$
A=\sqrt{\left(\frac{z_{1}}{\omega_{n}^{2}}\right)^{2}+\left(\frac{-z_{1} \zeta+\omega_{n}}{\omega_{n} \omega_{d}}\right)^{2}}, \beta=\arctan \left[\frac{\omega_{d} z_{1}}{\left(z_{1} \zeta-\omega_{n}\right) \omega_{n}}\right]
$$

The first term of (7) represents the steady-state frequency, and it can be expressed as

$$
f_{r_{-} \infty}=G_{0} \frac{z_{1}}{\omega_{n}^{2}}=\frac{R}{D R+1}
$$

The derivative of $f_{r}(t)$ stands for the changing rate of frequency, namely the ROCOF, which can be represented by the following equation:

$$
\frac{d}{d t} f_{r}(t)=G_{0}\left[\zeta \omega_{n} e^{-\zeta \omega_{n} t} \cdot A \cdot \sin \left(\omega_{d} t+\beta\right)-e^{-\zeta \omega_{n} t} \cdot A \omega_{d} \cdot \cos \left(\omega_{d} t+\beta\right)\right]
$$

Normally, the ROCOF at the instant of load change is more of concern, which takes the following form:

$$
\left.\frac{d}{d t} f_{r}(t)\right|_{t=0 s}=G_{0}\left[\zeta \omega_{n} A \cdot \sin (\beta)-A \omega_{d} \cdot \cos (\beta)\right]
$$

The time of frequency nadir, i.e., the peak time, can be easily derived by equaling (10) to zero:

$$
t_{\text {peak }}=\frac{1}{\omega_{d}}\left\{\arctan \left(\frac{\sqrt{1-\zeta^{2}}}{\zeta}\right)-\beta\right\}
$$

Substituting (12) into (7), the expression of frequency nadir can be derived and represented as follows:

$$
f_{r_{-} p e a k}=G_{0}\left\{\frac{z_{1}}{\omega_{n}^{2}}-e^{-\zeta \omega_{n} t_{p e a k}} \cdot A \cdot \sqrt{1-\zeta^{2}}\right\}
$$

An alternative of (13) is the expression of frequency overshoot, which can be derived based on (9) and (13) as

$$
\sigma=\left|\frac{f_{r_{-} \infty}-f_{r_{-} p e a k}}{f_{r_{-} \infty}}\right| \times 100 \%=\left|\frac{e^{-\zeta \omega_{n} t_{p e a k}} \cdot A \cdot \sqrt{1-\zeta^{2}} \cdot \omega_{n}^{2}}{z_{1}}\right| \times 100 \%
$$

In order to measure the dynamic performances of frequency regulation, the expression of settling time (time for entering $2 \%$ steady-state error band) is derived and listed as follows:

$$
\left|\frac{f_{r}\left(t_{s}\right)-f_{r_{-} \infty}}{f_{r_{-} \infty}}\right|=2 \% \Rightarrow \frac{\omega_{n}^{2} \cdot e^{-\zeta \omega_{n} t_{s}} \cdot A}{z_{1}}=2 \% \Rightarrow t_{s}=-\frac{1}{\zeta \omega_{n}} \cdot \ln \left(\frac{0.02\left|z_{1}\right|}{A \omega_{n}{ }^{2}}\right)
$$

Based on (11)-(15), variations of important performance indices, including the ROCOF, frequency nadir, overshoot, and settling time, versus inertia coefficient $H$, are presented in Figure 7. In Figure 7, both the diagrams of $T_{G}=7 \mathrm{~s}$ and $T_{G}=0.1 \mathrm{~s}$ are provided. As mentioned before, for the case of $T_{G}=7 \mathrm{~s}$, the damping factor $\zeta<1$ will always be satisfied. In contrast, $\zeta<1$ remains valid when $H<4.1 \mathrm{~s}$ for the case of $T_{G}=0.1 \mathrm{~s}$, and this condition can be derived from Figure 5a. As can be observed from Figure 7a, the ROCOF $\left|d f_{r} / d t\right| t=0 \mathrm{~s}$ decreases dramatically with the increase of $H$. A similar conclusion is also applicable to the absolute value of frequency nadir $\left|f_{r_{-} p e a k}\right|$ and overshoot $\sigma$, which 
are inversely proportional to $H$, as indicated by Figure $7 \mathrm{~b}, \mathrm{c}$. Additionally, it is noted from Figure $7 \mathrm{~d}$ that the settling time $t_{s}$ increases with the increase of $H$, which is reasonable since a large inertia coefficient would slow down the frequency dynamics. It can be concluded from the above analysis that a large $H$ helps to reduce the ROCOF, frequency deviation, and overshoot at the expense of increased settling time for the case of $\zeta<1$.

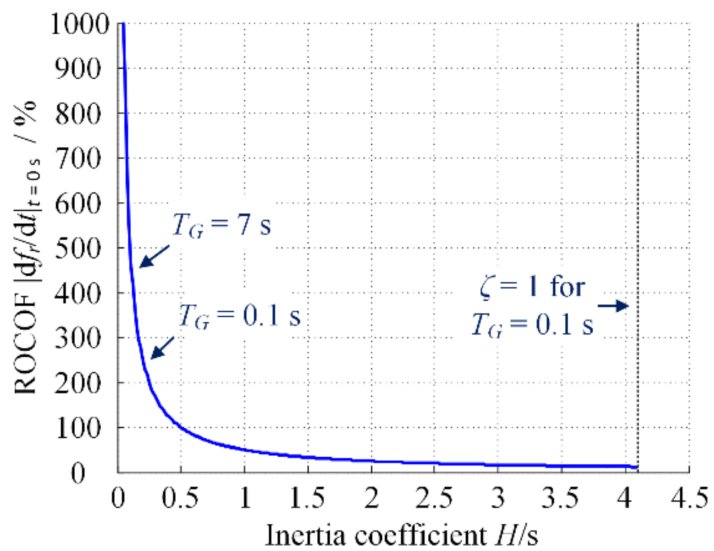

(a) ROCOF $\left|\mathrm{d} f_{r} / \mathrm{d} t\right| t=0 \mathrm{~s}$

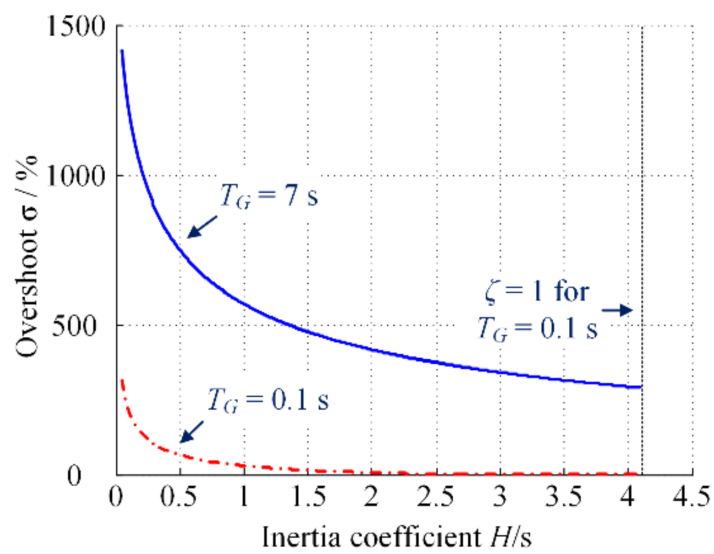

(c) Overshoot $\sigma$

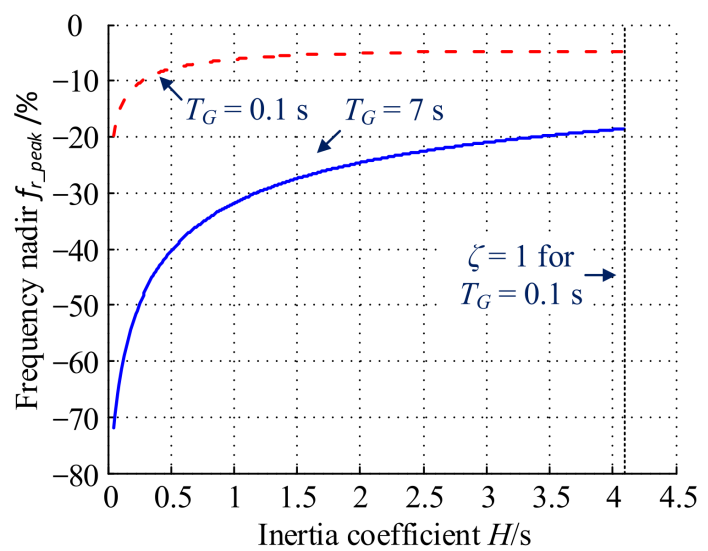

(b) Frequency nadir $f_{r_{-} \text {peak }}$

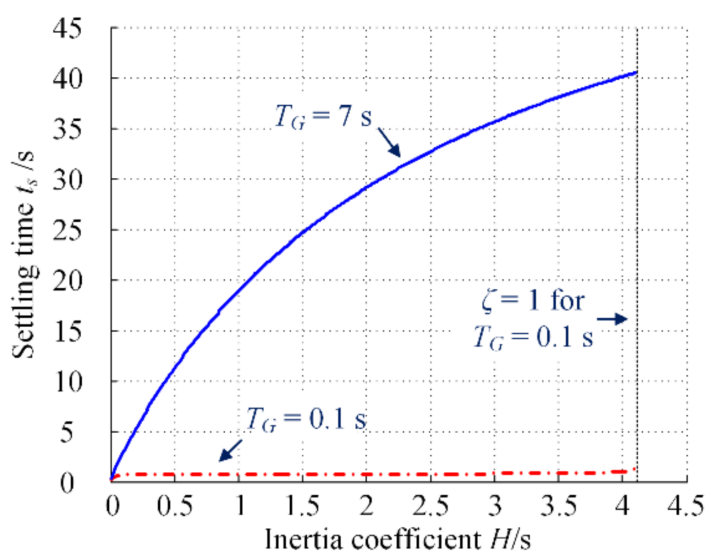

(d) Settling time $t_{s}$

Figure 7. Variations of important performance indices versus inertia coefficient $H$ for the case of $\zeta<1$.

\subsection{2. $\zeta=1$ Case}

For the case of $\zeta=1$, the system frequency response under a step-up load change can be expressed in the $s$-domain as

$$
f_{r}(s)=\frac{G_{P_{L} \rightarrow \omega}(s)}{s}=G_{0}\left\{\frac{1}{\left(s+\omega_{n}\right)^{2}}+\frac{z_{1}}{\omega_{n}^{2}}\left[\frac{1}{s}-\frac{s+\omega_{n}}{\left(s+\omega_{n}\right)^{2}}-\frac{\omega_{n}}{\left(s+\omega_{n}\right)^{2}}\right]\right\}
$$

Taking the inverse Laplace transform of (16), the time-domain expression of frequency response can be derived and represented as

$$
f_{r}(t)=L^{-1}\left[f_{r}(s)\right]=G_{0}\left[\frac{z_{1}}{\omega_{n}^{2}}-\frac{z_{1}}{\omega_{n}^{2}} e^{-\omega_{n} t}+\left(1-\frac{z_{1}}{\omega_{n}}\right) t e^{-\omega_{n} t}\right]
$$

The expression of the steady-state frequency remains unchanged, which is listed as

$$
f_{r_{-} \infty}=G_{0} \frac{z_{1}}{\omega_{n}^{2}}=\frac{R}{D R+1}
$$


The expression of ROCOF can be derived by differentiating (17) as

$$
\frac{d f_{r}(t)}{d t}=G_{0}\left[e^{-\omega_{n} t}-\omega_{n} t e^{-\omega_{n} t}+z_{1} t e^{-\omega_{n} t}\right]
$$

It can be concluded from (19) that $d f_{r}(t) / d t<0$ is always satisfied for the case of $\zeta=1$, and the relevant proof is detailed in Appendix A. This conclusion implies that the frequency nadir, peak time, and frequency overshoot will no longer exist for the case of $\zeta=1$. At time $t=0 \mathrm{~s}$, (19) changes into the following equation:

$$
\left.\frac{d f_{r}(t)}{d t}\right|_{t=0 s}=G_{0}=-\frac{1}{2 H}
$$

Equation (20) indicate that the ROCOF at $t=0 \mathrm{~s}$ for the case of $\zeta=1$ is only dependent on $H$. Moreover, the settling time can be expressed as

$$
\left|\frac{f_{r}\left(t_{s}\right)-f_{r_{-} \infty}}{f_{r_{-} \infty}}\right|=2 \% \Rightarrow\left(1+\omega_{n}-\frac{\omega_{n}^{2}}{z_{1}}\right) t_{s}=2 \% e^{\omega_{n} t_{s}}
$$

However, since (21) is a transcendental equation, its analytical solution does not exist. Alternatively, the numeric solution of $t_{s}$ should be employed to measure the system dynamics.

\subsection{3. $\zeta>1$ Case}

Considering a step-up load change for the case of $\zeta>1$, the system frequency response can be reorganized as

$$
f_{r}(s)=\frac{G_{P_{L} \rightarrow \omega}(s)}{s}=G_{0} \cdot\left[\frac{1}{s} \cdot \frac{z_{1}}{p_{1} p_{2}}+\frac{1}{s+p_{1}} \cdot \frac{z_{1}-p_{1}}{p_{2}-p_{1}} \cdot \frac{1}{\left(-p_{1}\right)}+\frac{1}{s+p_{2}} \cdot \frac{z_{1}-p_{2}}{p_{1}-p_{2}} \cdot \frac{1}{\left(-p_{2}\right)}\right]
$$

where $p_{1}$ and $p_{2}$ are the real poles of $f_{r}(s)$, which can be represented as

$$
p_{1}=\zeta \omega_{n}-\omega_{n} \sqrt{\zeta^{2}-1}, p_{2}=\zeta \omega_{n}+\omega_{n} \sqrt{\zeta^{2}-1}
$$

The expression of frequency response in the time domain can be derived from (22) and listed as below:

$$
f_{r}(t)=L^{-1}\left[f_{r}(s)\right]=G_{0} \cdot\left[\frac{z_{1}}{p_{1} p_{2}}+\frac{z_{1}-p_{1}}{p_{2}-p_{1}} \cdot \frac{1}{\left(-p_{1}\right)} e^{-p_{1} t}+\frac{z_{1}-p_{2}}{p_{1}-p_{2}} \cdot \frac{1}{\left(-p_{2}\right)} e^{-p_{2} t}\right]
$$

The steady-state frequency refers to the first term of (24), whose form is the same as (9) and (18) and can be expressed as

$$
f_{r_{-} \infty}=G_{0} \frac{z_{1}}{p_{1} p_{2}}=\frac{R}{D R+1}
$$

By differentiating (24) on both sides, the expression of ROCOF can be derived as follows:

$$
\frac{d f_{r}(t)}{d t}=G_{0} \cdot\left[\frac{z_{1}-p_{1}}{p_{2}-p_{1}} e^{-p_{1} t}+\frac{z_{1}-p_{2}}{p_{1}-p_{2}} e^{-p_{2} t}\right]
$$

Once again, it can be concluded that the sign of (26) remains to be negative, and the relevant proof is provided in Appendix A. This implies that the frequency nadir, peak time, and overshoot are meaningless for the case of $\zeta>1$. Moreover, the expression of ROCOF at $t=0 \mathrm{~s}$ remains unchanged, and it can be derived as

$$
\left.\frac{d f_{r}(t)}{d t}\right|_{t=0 s}=G_{0}=-\frac{1}{2 H} .
$$


Finally, the expression of settling time is listed below:

$$
\left|\frac{f_{r}\left(t_{s}\right)-f_{r_{-} \infty}}{f_{r_{-} \infty}}\right|=2 \% \Rightarrow\left|\frac{z_{1}-p_{1}}{p_{2}-p_{1}} \cdot \frac{p_{2}}{\left(-z_{1}\right)} e^{-p_{1} t_{s}}+\frac{z_{1}-p_{2}}{p_{1}-p_{2}} \cdot \frac{p_{1}}{\left(-z_{1}\right)} e^{-p_{2} t_{s}}\right|=0.02
$$

When $\left|p_{2}\right| /\left|p_{1}\right|>>1$, e.g., $\left|p_{2}\right| /\left|p_{1}\right|>5$, the term regarding to $e^{-p_{2} t_{s}}$ is relatively small, and hence, can be ignored. Under this condition, it is possible to derive the analytical solution of $t_{s}$ as

$$
\left|\frac{z_{1}-p_{1}}{p_{2}-p_{1}} \cdot \frac{p_{2}}{\left(-z_{1}\right)} e^{-p_{1} t_{s}}\right|=0.02 \Rightarrow t_{s}=\frac{\ln \left(0.02 \cdot \frac{p_{2}-p_{1}}{z_{1}-p_{1}} \cdot \frac{z_{1}}{p_{2}}\right)}{-p_{1}}
$$

For the case of $\zeta>1$, variations of performance indices versus the inertia coefficient $H$ are demonstrated in Figure 8. As compared with Figure 7, performance indices of frequency nadir and overshoot are excluded from Figure 8 because they are not meaningful due to the elimination of oscillations. Additionally, only the case of $T_{G}=0.1 \mathrm{~s}$ is analyzed here as $T_{G}=7 \mathrm{~s}$ will always lead to $\zeta<1$. As can be seen from Figure $8 \mathrm{a}$, the inverse proportional relationship between the ROCOF and inertia coefficient $H$ remains unchanged. However, it is clear that the ROCOF is greatly reduced as compared with that shown in Figure 7a. In other words, the ROCOF may not be a serious consideration for overdamped systems. Moreover, it is noted from Figure $8 \mathrm{~b}$ that the settling time increases linearly with the increase of inertia coefficient $H$ when $\zeta>1$. In conclusion, a larger inertia coefficient $H$ will increase the settling time and slightly reduce the ROCOF for the case of $\zeta>1$.

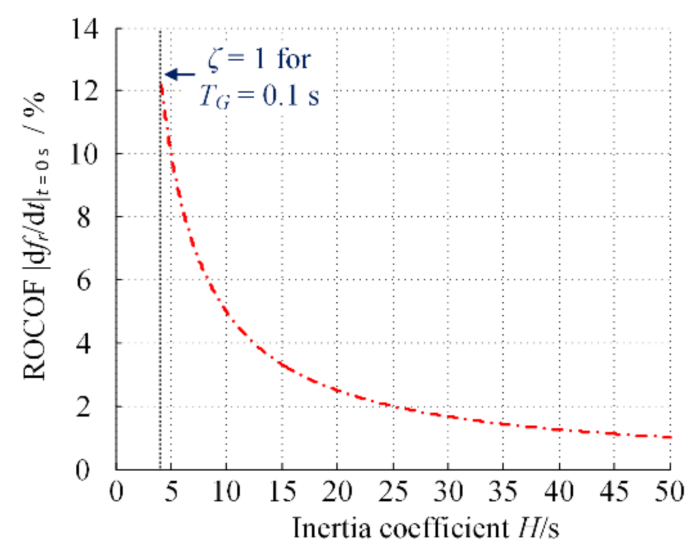

(a) ROCOF $\left|\mathrm{d} f_{r} / \mathrm{d} t\right| t=0 \mathrm{~s}$

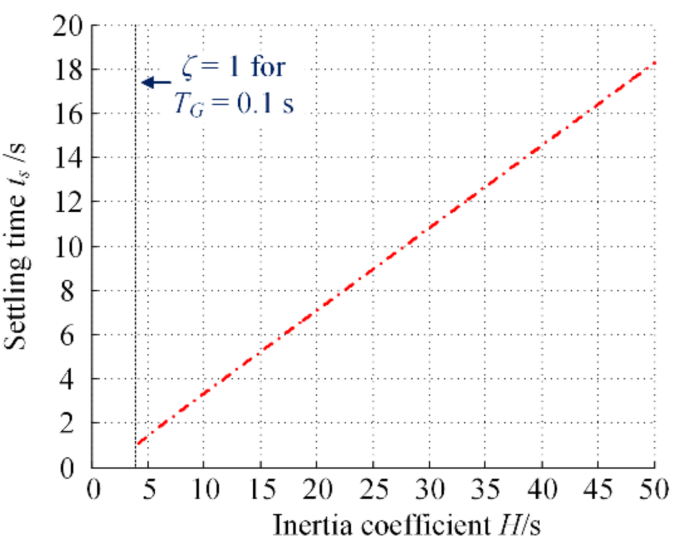

(b) Settling time $t_{\mathrm{s}}$

Figure 8. Variations of performance indices versus inertia coefficient $H$ for the case of $\zeta>1\left(T_{G}=0.1 \mathrm{~s}\right)$.

\section{Design of Inertia Coefficient}

This section focuses on the design of inertia coefficient $H$ based on the performance indices derived from Section 3. It is desirable to have fewer frequency oscillations and deviations as well as faster frequency recovery during frequency events. Therefore, the objectives of inertia design can be summarized as minimized ROCOF, frequency nadir or overshoot, and settling time. It should be mentioned that the requirement of frequency nadir and overshoot are essentially the same. The only difference is that frequency nadir varies as the change of percentage of load change, while overshoot specifies only the one hundred percent load change. In practice, grid codes often refer to the requirement of frequency nadir instead of overshoot. In any case, the requirements of ROCOF and frequency nadir must be strictly complied with so as to avoid undesirable load shedding or blackout. Under this circumstance, the settling time should be as low as possible. When designing the inertia coefficient $H$, it is assumed that the other parameters, $T_{G}, D$, and $R$, in Figure 3 and the existing inertia coefficient $H_{0}\left(H=H_{0}+\Delta H\right)$ are fixed and already known. 
Figure 9 show a design flowchart of inertia coefficient $H$. Based on the system parameters, the first step of design is to plot the diagram of $\zeta$ versus $H$ according to the fourth equation of (2), as shown in Figure 5. From this figure, the boundary condition of $H$ for $\zeta=1$, denoted as $H_{b}$, can be derived. The second step is to compare $H_{0}$ with $H_{b}$. If $H_{0}<H_{b}$, the case of $\zeta<1$ is satisfied. In contrast, if $H_{0}>H_{b}$, the case of $\zeta>1$ is satisfied. For the case of $H_{0}=H_{b}, \zeta=1$ can be obtained.

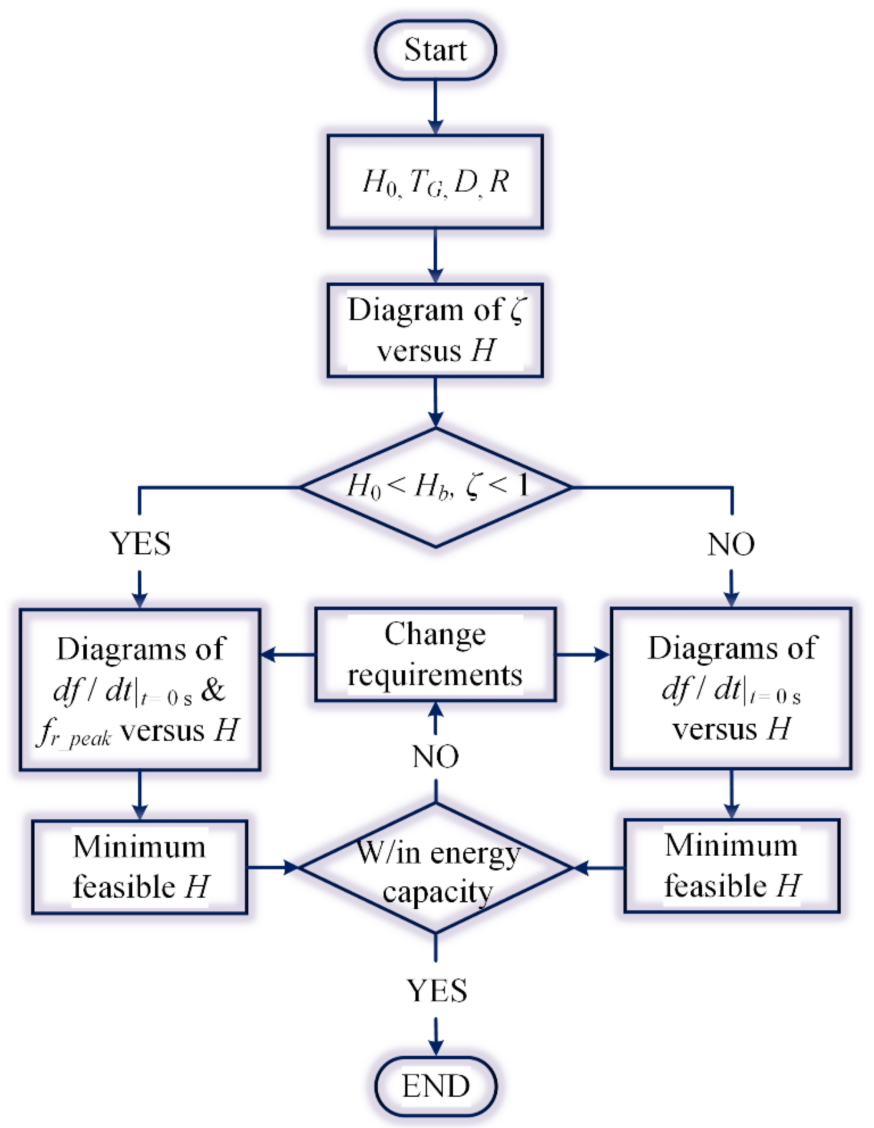

Figure 9. A design flowchart of inertia coefficient $H$.

The third design step will be different for different cases. In the $\zeta<1$ case, the diagrams of ROCOF and frequency nadir or overshoot should be drawn according to (11) and (13) or (14), respectively, as shown in Figure 7, in the third step. From this figure, the minimum value of $H$ required by ROCOF and frequency nadir or overshoot is finally selected in the fourth step; this $H$ also guarantees a relatively small value of $t_{s}$. Moreover, the maximum capacity of energy storage units dictates the maximum possible value of $H$. If this maximum value is less than the selected $H$, requirements should be modified, and $H$ should be selected again. For the cases of $\zeta=1$ and $\zeta>1$, the frequency nadir or overshoot will not exist, as mentioned in Section 3. Moreover, the satisfaction of requirements dictated by ROCOF can be relatively easy. It is possible to validate this requirement through plotting the diagram of ROCOF versus $H$ based on (27), as shown in Figure 8a. Considering that the settling time should be as low as possible, $H=H_{0}$ is normally the result of design for these cases.

Based on the system parameter values $H_{0}=5 \mathrm{~s}, D=1.0$, and $R=0.05$ listed in Table 1, two cases of $T_{G}=7 \mathrm{~s}$ and $T_{G}=0.1 \mathrm{~s}$ are, respectively, designed to comply with the requirements of ROCOF $\leq 0.5 \mathrm{~Hz} / \mathrm{s}$ and frequency nadir within $50 \pm 0.2 \mathrm{~Hz}$ under a $3 \%$ step-up load change. These requirements are translated into $\left|f_{r_{-} \text {peak }}\right| \leq 13.3 \%$ and $\left|\mathrm{d} f_{r}(\mathrm{t}) / \mathrm{d} t\right| t=0 \mathrm{~s} \leq 33.3 \%$ under a $100 \%$ load change. In the case of $T_{G}=7 \mathrm{~s}$, according to (11) and (13), the minimum feasible value, i.e., the selected value, of $H$ is $10 \mathrm{~s}$. In contrast, for the case of $T_{G}=0.1 \mathrm{~s}$, the requirements can be easily satisfied with $H=H_{0}=5 \mathrm{~s}$. 
Table 1. System parameter values.

\begin{tabular}{ccc}
\hline Description & Symbol & Value \\
\hline Droop coefficient & $R$ & 0.05 \\
Speed governor coefficient & $T_{G}$ & $7 / 0.1 \mathrm{~s}$ \\
Damping coefficient & $D$ & 1.0 \\
Inertia coefficient & $H$ & $10 / 5 \mathrm{~s}$ \\
Initial inertia coefficient & $H_{0}$ & $5 \mathrm{~s}$ \\
Rated frequency & $f_{\text {ref }}$ & $50 \mathrm{~Hz}$ \\
Maximum frequency nadir & $\mid f_{r}$ peak $\left.\right|_{\text {max }}$ & $0.2 \mathrm{~Hz}$ \\
Maximum ROCOF & $\left|d f_{r}(t) / d t\right|_{\text {max }}$ & $0.5 \mathrm{~Hz} / \mathrm{s}$ \\
Dc-link voltage & $V_{d c}$ & $400 \mathrm{~V}$ \\
Ac voltage (rms) & $V_{a}$ & $110 \mathrm{~V}$ \\
Switching frequency & $f_{s}$ & $10 \mathrm{kHz}$ \\
Dc-link capacitance & $C_{d c}$ & $2.82 \mathrm{mF}$ \\
Filter capacitance & $C_{f}$ & $5 \mu \mathrm{F}$ \\
Filter inductance & $L_{i} / L_{g}$ & $1.0 \mathrm{mH}$ \\
Power rating & $P_{\text {rated }}$ & $1 \mathrm{~kW}$ \\
\hline
\end{tabular}

\section{Experiment Verification}

Based on the system parameter values listed in Table 1, experiments were carried out on a 1-kW three-phase VSM prototype to validate the effectiveness of the proposed inertia analysis and design method. Figure 10 illustrate a photo of the experimental prototype. As seen, a three-phase $L C$-filtered power electronic converter was employed as the hardware of the VSM, while the control algorithms were executed on a dSPACE control platform (dSPACE Microlabbox). For simplicity, the VSM acts as the only generator fed by resistive loads, where transmission lines, transformers, and other factors are ignored. The energy storage of the VSM emulates the kinetic energy of the synchronous generator to support the islanded grid for frequency regulation. The frequency regulation structure of the VSM is presented in Figure 3, where the frequency variation signal $\Delta \omega_{r}$ was integrated to obtain the angle signal $\Delta \theta$. Then the ac output voltage reference $V_{\text {aref }}$ of the VSM can be determined according to $\Delta \theta$. A standard double-loop controller, i.e., outer voltage-loop and inner current-loop controller, was incorporated to achieve the voltage control of the VSM, and its design guideline can be found in [30].

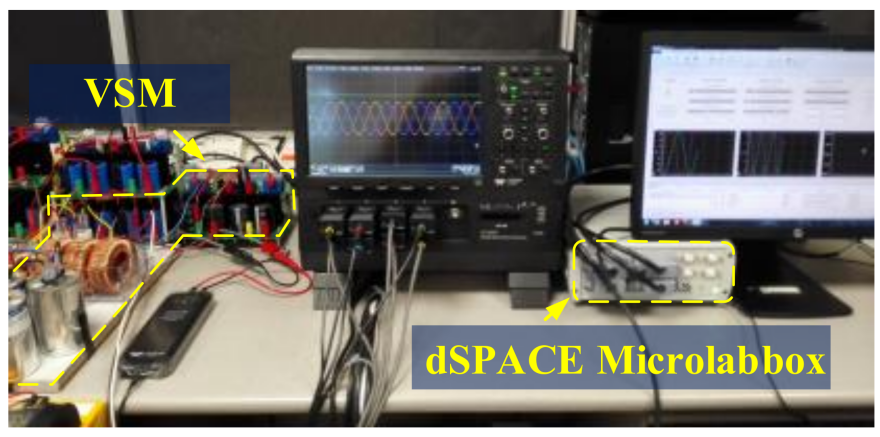

Figure 10. A photo of the experimental prototype.

Figure 11 demonstrate the steady-state experimental waveforms of the VSM. As seen, the VSM provides voltage support through converting the constant dc-link voltage vdc into three-phase ac output voltages $v_{x}(x=a, b, c)$ of sinusoidal waveforms. In the steady-state where the generated power, rated power of the VSM, and load power are equivalent, the frequency of $v_{x}(x=a, b, c)$ is the rated frequency of $50 \mathrm{~Hz}$. Since the load is purely resistive, the waveforms of load current follow those of ac voltages. 


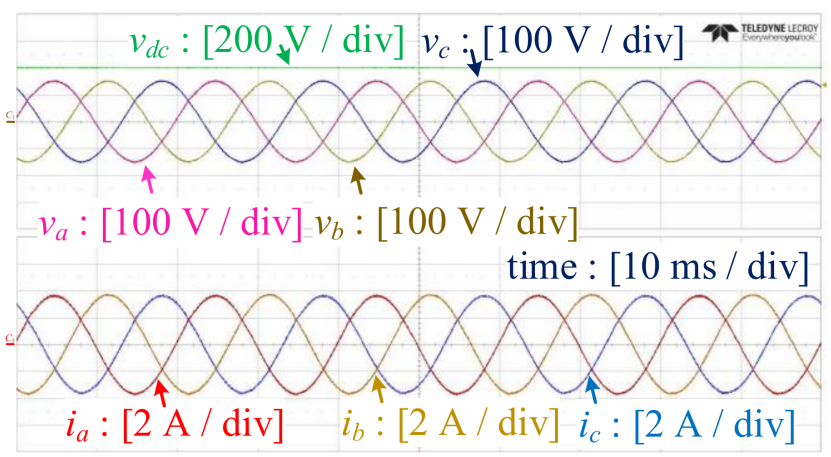

Figure 11. Steady-state experimental waveforms.

Under a 3\% step-up load change, frequency responses of the VSM with $T_{G}=7 \mathrm{~s}$ are shown in Figure 12. As seen, more frequency oscillations, larger frequency deviation and overshoot, and greater ROCOF can be observed for the case of $H=5 \mathrm{~s}$ as compared with the case of $H=10$ s, i.e., the case of optimal design. As mentioned in Section 3.2, a $T_{G}$ of $7 \mathrm{~s}$ specifies a relatively large time constant for the speed governor. Under this condition, the system always remains underdamped, i.e., $\zeta<1$. Consequently, most of the performance indices for frequency regulation, such as frequency nadir, overshoot, and ROCOF, can be improved as the inertia coefficient $H$, together with the damping factor $\zeta$, increases. It can be observed from Figure 12 that the requirement of frequency nadir is satisfied for the case of $H=10 \mathrm{~s}$. However, the case of $H=5 \mathrm{~s}$ fails to comply with this requirement even though it allows faster frequency recovery.

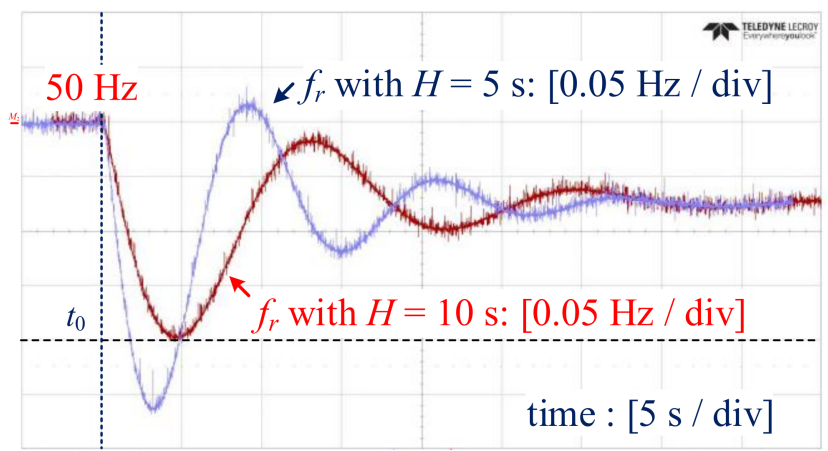

Figure 12. Experimental results of frequency regulation under a $3 \%$ step-up load change $\left(T_{G}=7 \mathrm{~s}\right)$.

In contrast, frequency responses of the VSM with $T_{G}=0.1 \mathrm{~s}$ under a $3 \%$ step-up load change are demonstrated in Figure 13. It is clear that all the requirements are satisfied for both the case of $H=5$ s, i.e., the optimal design, and the case of $H=10 \mathrm{~s}$. Being different from Figure 12, $T_{G}=0.1 \mathrm{~s}$ represents a condition that the time constant of speed governor is relatively small, where the system can be overdamped, i.e., $\zeta>1$. Under this condition, it is not advisable to employ a large inertia coefficient, e.g., $H=10 \mathrm{~s}$, because doing so will only slow down the frequency dynamics. Therefore, the proposed optimal design of inertia again leads to better frequency regulation performances.

To further illustrate this point, frequency responses of the VSM under a 3\% step-down load change when $T_{G}=7 \mathrm{~s}$ and $T_{G}=0.1 \mathrm{~s}$ are, respectively, presented in Figures 14 and 15 . Under this frequency event, the frequency $f_{r}$ becomes larger than its nominal value of $50 \mathrm{~Hz}$. Nevertheless, the expressions of performances indices derived in Section 3 are still applicable, and similar conclusions can be drawn from these figures. For the underdamped system (see Figure 14), a larger inertia coefficient is desirable as it translates into fewer oscillations. In contrast, a smaller $H$ is preferable for the overdamped system (see Figure 15) because it allows faster frequency recovery. 


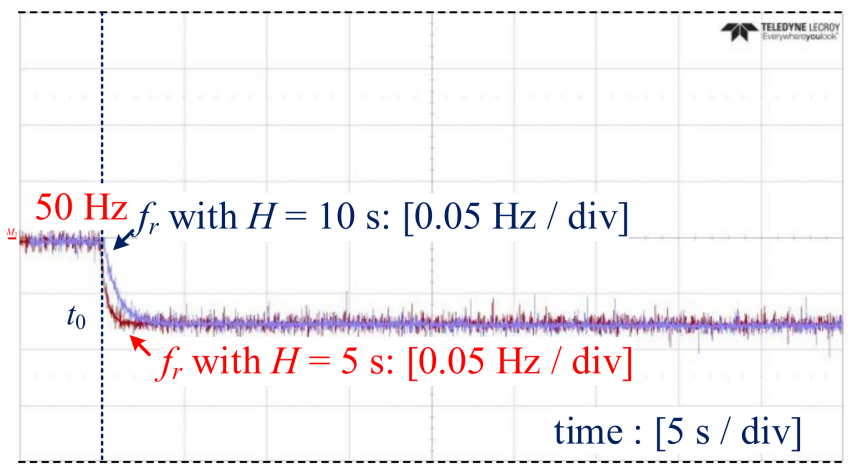

Figure 13. Experimental results of frequency regulation under a $3 \%$ step-up load change $\left(T_{G}=0.1 \mathrm{~s}\right)$.

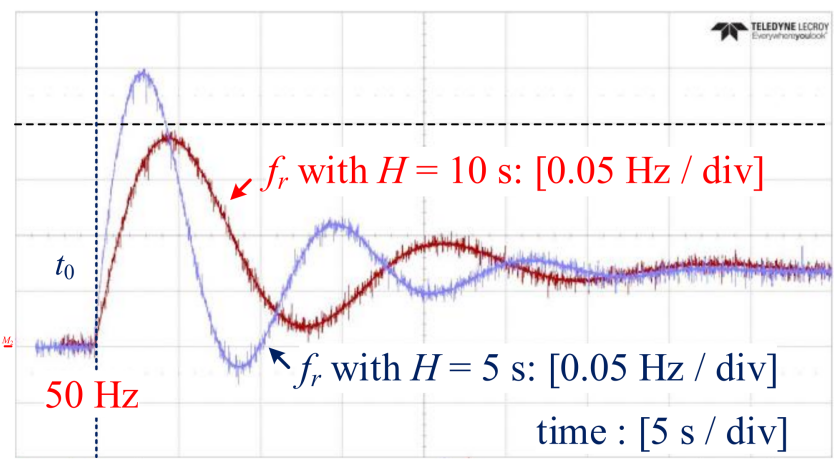

Figure 14. Experimental results of frequency regulation under a $3 \%$ step-down load change $\left(T_{G}=7 \mathrm{~s}\right)$.

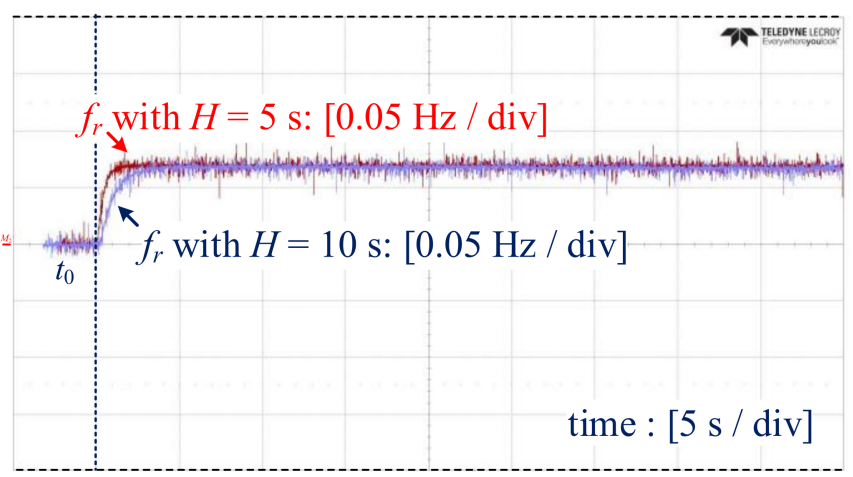

Figure 15. Experimental results of frequency regulation under a $3 \%$ step-down load change $\left(T_{G}=0.1 \mathrm{~s}\right)$.

\section{Conclusions}

It is identified in this paper that the design of inertia for EV chargers operating as VSMs in power electronics-based power systems, where the dominant generators are power converters instead of synchronous generators, can be different from the conventional power system. Because of the fast frequency regulation characterized by power converters, it is not necessary to employ a large inertia coefficient as a conventional design. Specifically, a larger inertia coefficient is desirable for an underdamped system, while a smaller one is preferable for an overdamped system. In order to illustrate this point, relationships between performances indices for frequency regulation, such as the rate-of-change-offrequency (ROCOF), frequency nadir, overshoot, settling time, and inertia coefficient, are derived. Based on these expressions, a design method that enables optimal performances of frequency regulation under different conditions is provided. Finally, experimental results obtained from a 1-kW virtual synchronous machine (VSM) prototype are presented to validate the effectiveness of the proposed method. 
Author Contributions: Conceptualization, J.F.; methodology, J.F.; software, J.F.; validation, C.L.; formal analysis, C.L.; data curation, C.L. and J.F.; writing-original draft preparation, C.L. and J.F.; writing-review and editing, C.L. and J.F.; visualization, C.L.; project administration, J.F.; funding acquisition, J.F. All authors have read and agreed to the published version of the manuscript.

Funding: This research was funded by Qilu Young Scholar Project, grant number 31400082163157. The project is supported by School of Control Science and Engineering, Shandong University.

Conflicts of Interest: The authors declare no conflict of interest.

\section{Appendix A}

First of all, the reasons for selecting $H>D T_{G} / 2$ instead of $H \leq D T_{G} / 2$ will be presented. As previously mentioned in Section 3.2 and indicated by (3), $H=D T_{G} / 2$ gives rise to the minimal value of $\zeta$, which indicates inadequate damping, and hence, this selection should be abandoned. In order to compare the effects of $H<D T_{G} / 2$ and $H>D T_{G} / 2$, system frequency responses with the same damping factor $\zeta=0.25$ and different time constants of speed governor $T_{G}=7 \mathrm{~s}$ and $T_{G}=0.1 \mathrm{~s}$ are, respectively, shown in Figure A1a,b. The values of $H$ involved in Figure A1a are $1.2 \mathrm{~s}$ and $10.2 \mathrm{~s}$, while these values are changed into $0.018 \mathrm{~s}$ and $0.145 \mathrm{~s}$ when plotting Figure A1b. It is clear from Figure A1 that the selection of $H<D T_{G} / 2$ inevitably leads to more oscillations and larger frequency deviations as compared with $H>D T_{G} / 2$. Consequently, $H \leq D T_{G} / 2$ should be avoided in practical design so as to reduce frequency deviations and their changing rates.

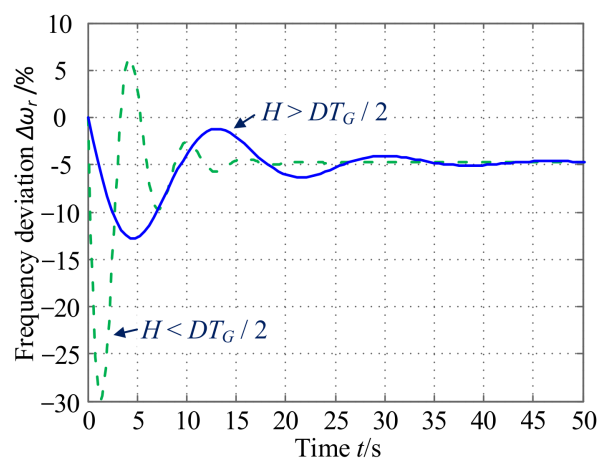

(a) $T_{G}=7 \mathrm{~s}$

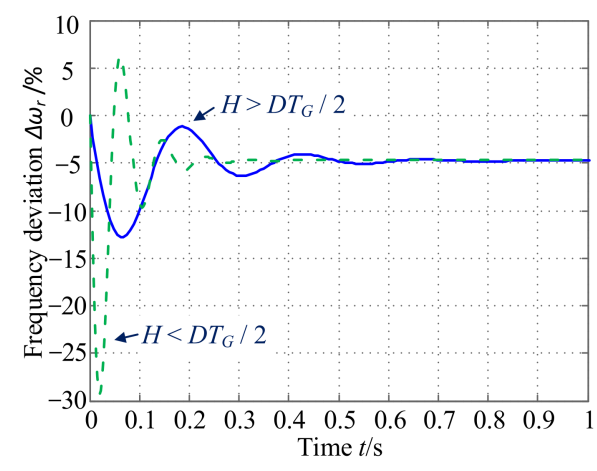

(b) $T_{G}=0.1 \mathrm{~s}$

Figure A1. Effects of $H<D T_{G} / 2$ and $H>D T_{G} / 2$ on system frequency regulation under a step-up load change $(\zeta=0.25)$.

\section{Appendix A.1. Proof of $d f_{r}(t) / d t<0$ for $\zeta=1$ Case}

It is concluded in Section 3.2 that $d f_{r}(t) / d t<0$ can be derived from (19). This conclusion will be proved by contradiction. Assuming that $d f_{r}(t) / d t \geq 0$ is valid and substituting this inequality into (19), the following inequality can be obtained:

$$
G_{0}\left[e^{-\omega_{n} t}-\omega_{n} t e^{-\omega_{n} t}+z_{1} t e^{-\omega_{n} t}\right] \geq 0
$$

Since $G_{0}<0$, inequality (A1) can be simplified into

$$
1+\left(z_{1}-\omega_{n}\right) t \leq 0
$$

In order to solve (A2), the relationship between $\omega_{n}$ and $z_{1}$ should be derived. Substituting $\zeta=1$ into the fourth equation of (2), and then it becomes:

$$
\frac{\left(2 H+D T_{G}\right)}{4 H T_{G}} \sqrt{\frac{2 H R T_{G}}{D R+1}}=1 \Rightarrow \frac{\left(2 H+D T_{G}\right)}{4 H T_{G}}=\omega_{n} \Rightarrow \omega_{n}=\frac{1}{2 T_{G}}+\frac{D}{4 H} \Rightarrow \omega_{n}=\frac{z_{1}}{2}+\frac{D}{4 H}
$$


Considering the prerequisite that $H>D T_{G} / 2=D / 2 z_{1}$, the following relationship between $\omega_{n}$ and $z_{1}$ is obtained:

$$
\omega_{n}<\frac{z_{1}}{2}+\frac{z_{1}}{2}=z_{1}
$$

Substituting (A4) into (A2), the satisfactory region of time $t$ can be derived as

$$
t \leq \frac{-1}{\left(z_{1}-\omega_{n}\right)}<0
$$

In practice, the value of time $t$ should always be positive. Therefore, the assumption that $d f_{r}(t) / d t \geq 0$ is incorrect, and hence, $d f_{r}(t) / d t<0$ must be satisfied.

\section{Appendix A.2. Proof of $d f r(t) / d t<0$ for $\zeta>1$ Case}

The conclusion that the sign of (26) is negative will be proved as follows. First of all, $p_{2}>p_{1}>0$ and $\mathrm{e}^{-p 1 t}>\mathrm{e}^{-p 2 t}>0$ can be readily observed from (23). Considering that $z_{1}=1 / T_{G}>0$, there are three possible relationships among $p_{1}, p_{2}$, and $z_{1}$, i.e., $z_{1}>p_{2}>p_{1}$, $p_{2}>z_{1}>p_{1}$, and $p_{2}>p_{1}>z_{1}$. For the first case $z_{1}>p_{2}>p_{1}$, the following inequality can be derived:

$$
\frac{z_{1}-p_{1}}{p_{2}-p_{1}} e^{-p_{1} t}>\frac{z_{1}-p_{1}}{p_{2}-p_{1}} e^{-p_{2} t}>\frac{z_{1}-p_{2}}{p_{2}-p_{1}} e^{-p_{2} t}>0
$$

Based on (A6) and the fact that $G_{0}<0$, the sign of (26) can be obtained as negative using the following equation:

$$
\frac{d f_{r}(t)}{d t}=G_{0} \cdot\left[\frac{z_{1}-p_{1}}{p_{2}-p_{1}} e^{-p_{1} t}-\frac{z_{1}-p_{2}}{p_{2}-p_{1}} e^{-p_{2} t}\right]<0
$$

For the second case, $p_{2}>z_{1}>p_{1}$, it is clear that the following inequalities are satisfied:

$$
\frac{z_{1}-p_{1}}{p_{2}-p_{1}} e^{-p_{1} t}>0, \frac{z_{1}-p_{2}}{p_{1}-p_{2}} e^{-p_{2} t}>0
$$

Therefore,

$$
\frac{d f_{r}(t)}{d t}=G_{0} \cdot\left[\frac{z_{1}-p_{1}}{p_{2}-p_{1}} e^{-p_{1} t}+\frac{z_{1}-p_{2}}{p_{1}-p_{2}} e^{-p_{2} t}\right]<0
$$

The analysis provided hereafter will indicate that the third case $p_{2}>p_{1}>z_{1}$ would not exist under the prerequisite that $H>D T_{G} / 2=D / 2 z_{1}$. Similarly, this part will be proved by contradiction. Assuming that $p_{2}>p_{1}>z_{1}$, the following inequality satisfies:

$$
2 z_{1}<p_{1}+p_{2}=2 \zeta \omega_{n}=\frac{\left(2 H+D T_{G}\right)}{2 H T_{G}}
$$

Inequality (A10) can be further expressed as

$$
2 \frac{1}{T_{G}}<\frac{\left(2 H+D T_{G}\right)}{2 H T_{G}} \Rightarrow H<\frac{D T_{G}}{2}
$$

Since (A11) is contradictory to the prerequisite that $H>D T_{G} / 2$, the assumption that $p_{2}>p_{1}>z_{1}$ is incorrect. In conclusion, $d f_{r}(t) / d t<0$ should always be satisfied under the condition that $\zeta \geq 1$.

\section{References}

1. Blaabjerg, F.; Chen, Z; Kjaer, S.B. Power electronics as efficient interface in dispersed power generation systems. IEEE Trans. Power Electron. 2004, 19, 1184-1194. [CrossRef]

2. Emadi, A.; Williamson, S.S.; Khaligh, A. Power electronics intensive solutions for advanced electric, hybrid electric, and fuel cell vehicular power systems. IEEE Trans. Power Electron. 2006, 21, 567-577. [CrossRef] 
3. Yilmaz, M.; Krein, P.T. Review of battery charger topologies, charging power levels, and infrastructure for plug-in electric and hybrid vehicles. IEEE Trans. Power Electron. 2013, 28, 2151-2169. [CrossRef]

4. Zhong, Q. Power electronics-enabled autonomous power systems: Architecture and technical routes. IEEE Trans. Ind. Electron. 2017, 64, 5907-5918. [CrossRef]

5. Kundur, P. Power System Stability and Control; McGraw-Hill: New York, NY, USA, 1994.

6. Blaabjerg, F.; Teodorescu, R.; Liserre, M.; Timbus, A.V. Overview of control and grid synchronization for distributed power generation systems. IEEE Trans. Ind. Electron. 2006, 53, 1398-1409. [CrossRef]

7. Delille, G.; Francois, B.; Malarange, G. Dynamic frequency control support by energy storage to reduce the impact of wind and solar generation on isolated power system's inertia. IEEE Trans. Sustain. Energy 2012, 3, 931-939. [CrossRef]

8. Carrasco, J.M.; Franquelo, L.G.; Bialasiewicz, J.T.; Galvan, E.; PortilloGuisado, R.C.; Prats, M.A.M.; Leon, J.I.; Moreno-Alfonso, N. Power-electronic systems for the grid integration of renewable energy sources: A survey. IEEE Trans. Ind. Electron. 2006, 53, 1002-1016. [CrossRef]

9. Arani, M.F.M.; EI-Saadany, E.F. Implementing virtual inertia in DFIG-based wind power generation. IEEE Trans. Power Syst. 2013, 28, 1373-1384. [CrossRef]

10. Driesen, J.; Visscher, K. Virtual synchronous generators. In Proceedings of the 2008 IEEE Power \& Energy Society General Meeting, Pittsburgh, PA, USA, 20-24 July 2008.

11. Beck, H.P.; Hesse, R. Virtual synchronous machine. In Proceedings of the 9th International Conference on Electrical Power Quality and Utilisation, Barcelona, Spain, 9-11 October 2007.

12. Zhong, Q.; Weiss, G. Synchronverters: Inverters that mimic synchronous generators. IEEE Trans. Ind. Electron. 2011, 58, 1259-1267. [CrossRef]

13. Zhong, Q.; Nguyen, P.; Ma, Z.; Sheng, W. Self-synchronized synchronverters: Inverters without a dedicated synchronization unit. IEEE Trans. Power Electron. 2014, 29, 617-630. [CrossRef]

14. Shintai, T.; Miura, Y.; Ise, T. Oscillation damping of a distributed generator using a virtual synchronous generator. IEEE Trans. Power Del. 2014, 29, 668-676. [CrossRef]

15. Suul, J.A.; Arco, S.D.; Guidi, G. Virtual synchronous machine-based control of a single-phase bi-directional battery charger for providing vehicle-to-grid services. IEEE Trans. Ind. Appl. 2016, 52, 3234-3244. [CrossRef]

16. Guan, M.; Pan, W.; Zhang, J.; Hao, Q.; Cheng, J.; Zheng, X. Synchronous generator emulation control strategy for voltage source converter (VSC) stations. IEEE Trans. Power Syst. 2015, 30, 3093-3101. [CrossRef]

17. Frack, P.F.; Mercado, P.E.; Molina, M.G.; Watanabe, E.H.; Doncker, R.W.D.; Stagge, H. Control strategy for frequency control in autonomous microgrids. IEEE J. Emerg. Sel. Top. Power Electron. 2015, 3, 1046-1055. [CrossRef]

18. Arco, S.D.; Suul, J.A. Equivalence of virtual synchronous machines and frequency-droops for converter-based microgrids. IEEE Trans. 2014, 5, 394-395.

19. Ashabani, M.; Mohamed, Y.A.I. Integrating VSCs to weak grids by nonlinear power damping controller with self-synchronization capability. IEEE Trans. Power Syst. 2014, 29, 805-814. [CrossRef]

20. Ashabani, M.; Mohamed, Y.A.I. Novel comprehensive control framework for incorporating VSCs to smart power grids using bidirectional synchronous-VSC. IEEE Trans. Power Syst. 2014, 29, 943-957. [CrossRef]

21. Liu, J.; Miura, Y.; Ise, T. Comparison of dynamic characteristics between virtual synchronous generator and droop control in inverter-based distributed generators. IEEE Trans. Power Electron. 2016, 31, 3600-3611. [CrossRef]

22. Liu, J.; Miura, Y.; Bevrani, H.; Ise, T. Enhanced virtual synchronous generator control for paralleled inverters in microgrids. IEEE Trans. Smart Grid. 2017, 8, 2268-2277. [CrossRef]

23. Hirase, Y.; Sugimoto, K.; Sakimoto, K.; Ise, T. Analysis of resonance in microgrids and effects of system frequency stabilization using a virtual synchronous generator. IEEE J. Emerg. Sel. Top. Power Electron. 2016, 4, 1287-1298. [CrossRef]

24. Fang, J.; Li, H.; Tang, Y.; Blaabjerg, F. Distributed power system virtual inertia implemented by grid-connected power converter. IEEE Trans. Power Electron. 2018, 33, 8488-8499. [CrossRef]

25. Fu, S.; Sun, Y.; Liu, Z.; Hou, X.; Han, H.; Sun, M. Power oscillation suppression in multi-VSG grid with adaptive virtual inertia. Int. J. Electr. Power Energy Syst. 2022, 135, 107472. [CrossRef]

26. Soni, N.; Doolla, S.; Chandorkar, M.C. Improvement of transient response in microgrids using virtual inertia. IEEE Trans. Power Del. 2013, 28, 1830-1838. [CrossRef]

27. Alipoor, J.; Miura, Y.; Ise, T. Power system stabilization using virtual synchronous generator with alternating moment of inertia. IEEE J. Emerg. Sel. Top. Power Electron. 2015, 3, 451-458. [CrossRef]

28. Torres, M.A.; Lopes, L.A.C.; Moran, T.L.A.; Espinoza, C.J.R. Self-tuning virtual synchronous machine: A control strategy for energy storage systems to support dynamic frequency control. IEEE Trans. Energy Convers. 2014, 29, 833-840. [CrossRef]

29. D'Arco, S.; Suul, J.A.; Fosso, O.B. A virtual synchronous machine implementation for distributed control of power converters in smart grid. Electr. Power Syst. Res. 2015, 122, 180-197. [CrossRef]

30. Zhang, K.; Kang, Y.; Xiong, J.; Chen, J. Direct repetitive control of SPWM inverter for UPS purpose. IEEE Trans. Power Electron. 2003, 18, 784-792. [CrossRef] 